Sharif University of Technology
Scientia Iranica
SCIENTIA $\quad \begin{gathered}\text { Transactions D: Computer Science ES Engineering and Electrical Engineering } \\ \text { http://scientiairanica.sharif.edu }\end{gathered}$

\title{
A comparative study of economic load dispatch with complex non-linear constraints using salp swarm algorithm
}

\author{
K. Bhattacharjee* and N. Patel \\ Institute of Technology, Electrical Engineering Department, Nirma University, Ahmedabad, Gujarat, India.
}

Received 2 November 2018; received in revised form 14 September 2019; accepted 11 May 2020

KEYWORDS
Economic load
dispatch;
Optimization;
Prohibited operating
zone;
Salp swarm algorithm;
Valve-point loading.

\section{Introduction}

Economic Load Dispatch (ELD) is considered one of the valued optimization problems in the field of power system operations. The ELD satisfies the total load demand by economically allocating the load demand to each and every generator while satisfying their operation and physical constraints. The ELD helps satisfy the total load demand in the most economical way. The main objective of the ELD is to make the entire system reliable and minimize the total generation cost of the thermal power plant. However, the ELD

\footnotetext{
*. Corresponding author. Tel.: +919832832822

E-mail addresses: kuntal.bhattacharjee@nirmauni.ac.in (K. Bhattacharjee); 16meee18@nirmauni.ac.in (N. Patel)
}

satisfies all the constraints of each and every generator that is considered for the ELD problem.

There are many classic optimization methods including gradient method [1], Quadratic Programming (QP) [2], Lagrangian relaxation [3], Hopfield modeling framework [4], Linear Programming (LP) [5], and Dynamic Programming (DP) [6] that assume a linear increasing cost function and they have been successfully applied to solve the ELD problem. However, the main problem with the classical approach is that it tends to converge at a local optimum and then, begins to diverge from the global optimal solution. The problem with dynamic programming approach is that it requires very large dimensions and consequently, much programming effort. These classical methods are not able to locate the global optimum solution because of the presence of many non-linear equations like the nonsmooth cost function, ramp rate limit, and discontinu- 
ous prohibited operating zones. Moreover, due to the non-linear characteristic of the ELD problem, many of the classic optimization method techniques cannot reach the global optimal solution and tend to diverge in a local optimum solution. Therefore, it becomes imperative to develop an optimization technique that can overcome these drawbacks of the classical based methods and give the global optimum solution in the least computation time. Many artificial intelligence algorithms like the Hopfield Neural Network (HNN) [7] have been employed to solve the ELD problem. The problem with artificial intelligence algorithms is that they take a large number of iterations to reach the global optimum solution, because the algorithms must converge to the global optimum value and the rate of convergence of these algorithms varies. Due to the difference in the rate of convergence, the time duration taken by different algorithms is different. Hence, a longer time is required to reach the global solution. The computer technology has developed many new population-based heuristic optimization techniques like Differential Evolution (DE) [8], Evolutionary Programming (EP) [9], Hybrid Evolutionary Programming (HEP) [10], Particle Swarm Optimization (PSO) [11], Civilized Swarm Optimization (CSO) [12], Crazinessbased PSO (CRPSO) [13], Hybrid PSO (HPSO) [14], Modified PSO (MPSO) [15], Genetic Algorithm (GA) [16], Hybrid GA (HGA) [17], Adaptive Real Coded GA (ARCGA) [18], Bacteria Foraging Optimization (BFO) [19], Modified BFO (MBFO) [20], modified Artificial Bee Colony (ABC) [21], Seeker Optimization Algorithm (SOA) [22], Ant Colony Optimization (ACO) [23], Tabu Search (TS) [24], Biogeography Based Optimization (BBO) [25], and QuasiOppositional BBO (QOBBO) [26], Oppositional BBO (OBBO) [27], and Harmony Search Algorithm (HSA) [28] for solving ELD problems. Other optimization algorithms, including the Opposition-based Harmony Search Algorithm (OHSA) introduced by Chatterjee et al., have been proposed to solve the ELD problem [29]. Krill Herd Algorithm (KHA) [30] was successfully applied to solve the ELD problems. The problem of short-term hydrothermal scheduling was solved using the SCA technique in [31]. An enhanced version of Particle Swarm Optimization was proposed in [32] to solve the problem of ELD. A new technique maximum likelihood optima technique was also used to solve the ELD problem in [33]. Group Leader Optimization [34] was proposed because of its special ability to solve the non-linear and non-quadratic equations with greater ease. Even Teaching Learning Based Optimization (TLBO) technique was used in [35] to solve the ELD problem. Some of the above-mentioned algorithms run into difficulty finding a local optimum solution, while others have difficulty finding the global optimum solution. Therefore, to overcome this kind of problem, a new and powerful optimization technique is needed. Even the Simulated Annealing Algorithm (SAA) was employed to solve the economic emission dispatch problem in [36]. Moreover, the enhanced vibrating particles system algorithm was employed to identify the damage to the truss structure in [37]. A new algorithm called ameliorated grey wolf optimization [38] has been recently introduced that could solve the ELD problem. The hybrid artificial algae algorithm was used in [39] to solve the ELD problem. In [40] and [41], the artificial cooperative search algorithm and phasor particle swarm optimization were respectively introduced to solve the ELD problem. Bhattacharjee et al. [42] used the opposition-based krill herd algorithm, while others [43] utilized the adaptive differential evolutionary algorithm to find a solution to the ELD problem.

Recently, a new algorithm called Salp Swarm Algorithm (SSA) [44] has been proposed based on the movement of salps in the sea. The search agent having the maximum fitness is made to move towards the global optima. The SSA is considered superior due to its exploration and exploitation properties and it is utilized to reach the global optimal value within the least computation time. Due to its exploration and exploitation properties, SSA avoids local optimum and tends to move directly towards the global optimum value. Lately, some efficient modified and hybrid optimization techniques [45-50] have also been used to solve ELD problems more efficiently. With a new concept, there are some recent techniques [51-61] that are actively able to solve the ELD problem with much more complex constraints.

Section 2 of the paper states the problem formulation of various ELD problems with different feasible constraints. The conception of the SSA is described in Section 3. The performance of the SSA under various test systems and the simulation studies are discussed in Section 4. Lastly, conclusion is drawn in Section 5.

\section{Problem formulation}

The problems of ELD are expressed as convex or non-convex problems with some linear and nonlinear constraints for different applications.

The objective function of ELD with quadratic cost function based on Eq. (1) is given below [44]:

$$
F_{C o s t}=\min \sum_{a=1}^{N}\left(\alpha_{a}+\beta_{a} P_{a}+\gamma_{a} P_{a}^{2}\right) \text {. }
$$

For realistic and practical application of ELD problem, the smooth quadratic cost function has been modified by adding sinusoidal terms of ripple input-output curve with valve point effects. The valve point effect-based cost function of ELD is given below [44]: 


$$
\begin{aligned}
F_{\text {Cost }}= & \min \sum_{a=1}^{N}\left(\alpha_{a}+\beta_{a} P_{a}+\gamma_{a} P_{a}^{2}\right. \\
& \left.+\left|\delta_{a} \times \sin \left\{\varepsilon_{a}\left(P_{a}^{\min }-P_{a}\right)\right\}\right|\right),
\end{aligned}
$$

where $\alpha_{a}, \beta_{a}, \gamma_{a}, \delta_{a}$, and $\varepsilon_{a}$ are the constant values of fuel cost function. $N$ is the total number of thermal generators. Power generation of each generator is $P_{a}$. Lower and higher limits of power generation are characterized by $P_{a}^{\min }$ and $P_{a}^{\max }$, respectively. Power generation of each unit follows the generating capacity constraint:

$$
P_{a}^{\min } \leq P_{a} \leq P_{a}^{\max } .
$$

This is the inequality constraint of ELD problems. The equality constraints or real power balance constraint of ELD is based on Eq. (4):

$$
\sum_{a=1}^{N} P_{a}-P_{D}-P_{\text {Loss }}=0
$$

where $P_{D}$ is the total system active power demand; total transmission loss $P_{\text {Loss }}$ is calculated by using the $B$-matrix loss coefficients as expressed below [59]:

$$
P_{\text {Loss }}=\sum_{a=1}^{N} \sum_{b=1}^{N} P_{a} B_{a b} P_{b}+\sum_{a=1}^{N} B_{0 a} P_{a}+B_{00} .
$$

Ramp rate limit is another constraint that has been considered in solving ELD problems to increase the lifespan of generators as given below:

$$
\begin{aligned}
& P_{a}-P_{a 0} \leq U R_{a} \quad(\text { as generation rises }), \\
& P_{a 0}-P_{a} \leq D R_{a} \quad(\text { as generation declines }), \\
& \max \left(P_{a}^{\min }, P_{a 0}-D R_{a}\right) \leq \min \left(P_{a}^{\max }, P_{a 0}+U R_{a}\right),
\end{aligned}
$$

where $P_{a 0}$ is the power generation of the $a$ th previous interval; $U R_{a}$ and $D R_{a}$ are the up-ramp and downramp limits, respectively.

Different faults in the machines, boilers, feed pumps, steam valve operation, and vibration in the bearing, etc. and also such constraints as Prohibited Operating Zone (POZ) have been considered in dealing with ELD problems. Mathematically, POZ can be expressed as follows:

$$
\begin{aligned}
& P_{a}^{\min } \leq P_{a} \leq P_{a, 1}^{l}, \\
& P_{a, j-1}^{u} \leq P_{a} \leq P_{a, j}^{l}, \\
& P_{a, n}^{u} \leq P_{a} \leq P_{a}^{\max }, \\
& j=1 \text { to } n,
\end{aligned}
$$

where $P_{a, j}^{u}$ and $P_{a, j}^{l}$ represent the upper and lower limits of the $j$ th prohibited operating zone of the $a$ th unit. Total number of prohibited operating zones of the $a$ th unit is $n$.

For a system with $n$ generators and having $n_{F}$ fuel options for each unit, the entire cost function is expressed as follows:

$$
\begin{aligned}
F_{i p}\left(P_{i}\right)= & a_{i p}+b_{i p} P_{i}+c_{i p} P_{i^{2}} \\
& +\left|e_{i p} \times \sin \left\{f_{i p} \times\left(p_{i p}^{\min }-P_{i}\right)\right\}\right|,
\end{aligned}
$$

where $p=1,2, \cdots, n_{F}$. Calculation of slack generator is one of the important parts in ELD problem formulations. If $N$ is the total number of generators, then the $(N-1)$ number of power generations is initially calculated randomly based on Inequalities (3), (6), (7), (8), and (9). The remaining generator (let $N$ th) called slack generator must be evaluated using Eq. (4). The value of slack generator is given below:

Without transmission losses:

$$
P_{N}=P_{D}-\sum_{a=1}^{N-1} P_{a}
$$

With transmission losses:

$$
P_{N}=P_{D}+P_{\text {Loss }}-\sum_{a=1}^{N-1} P_{a} .
$$

Transmission loss $\left(P_{\text {Loss }}\right)$ is also related to power generations based on Eq. (5); therefore, Eq. (11) is further modified and is given below:

$$
\begin{aligned}
B_{N N} P_{N}^{2} & +P_{N}\left(2 \sum_{a=1}^{N-1} B_{N a} P_{a}+\sum_{a==1}^{N-1} B_{0 N}-1\right) \\
& +\left(P_{D}+\sum_{a=1}^{N-1} \sum_{b=1}^{N-1} P_{a} B_{a b} P_{b}+\sum_{a=1}^{N-1} B_{0 a} P_{a}\right. \\
& \left.-\sum_{a=1}^{N-1} P_{a}+B_{00}\right)=0 .
\end{aligned}
$$

In this study, the authors are considering static ELD problem formulation. Rather than the static ELD problem, the dynamical ELD one with a spinning reserve can be considered as a complex constraint. Similarly, for some durations like any day, i.e., 24 hours, different constraints like start-up cost and mustrun cost can be considered as constraints in the unit commitment problem formulation. Whenever this type of complex constraint is included, the overall problem formulation will be more complex and the SSA algorithm can, therefore, be applied to this type of complex formulation, as well. Due to lack of space, these are not considered in the study. 


\section{Salp swarm algorithm}

The SSA [44] is a population-based optimization technique. It is inspired by the movement of the salps in the ocean. They move in a swarm of population. The entire population is divided into two groups: leader and followers. The leader is the salp and is in front of the chain, while the rest of the salps are considered the followers. The leader slap guides the entire swarm of salps towards the destination. The position of salps is defined in an $n$-dimensional search space where $n$ is the number of variables of a given problem. Thus, the positions of all salps are stored in a two-dimensional matrix called $x$. It is also assumed that there is a food source called $F$ in the search space as the swarm's target.

To update the position of the leader, the following equation is proposed:

$$
x_{j}^{1}=\left\{\begin{array}{l}
F_{j}+c_{1}\left(\left(u b_{j}-l b_{j}\right) c_{2}+l b_{j}\right) \\
F_{j}-c_{1}\left(\left(u b_{j}-l b_{j}\right) c_{2}+l b_{j}\right)
\end{array}\right.
$$

where $x_{j}^{1}$ denotes the position of the first salp (leader) in the $j$ th dimension, $F_{j}$ the position of the food source in the $j$ th dimension, $u b_{j}$ the upper bound of the $j$ th dimension, and $l b_{j}$ the lower bound of the $j$ th dimension.

This equation proves that the leader updates its position with respect to the food source. The coefficient $c_{1}$ is the most important parameter in SSA because it balances exploration and exploitation defined as follows:

$$
c_{1}=2 \times e \frac{-4 l}{L},
$$

where $l$ is the current iteration and $L$ is the maximum number of iterations. The parameters $c_{2}$ and $c_{3}$ are random numbers uniformly generated at the interval of $[0,1]$ and $[-1,1]$, respectively. In fact, they dictate if the next position in the $j$ th dimension should be towards positive infinity or negative infinity as well as the step size. More details of these parameters can be found in [44]. To update the position of the followers, the following equations are utilized:

$$
x_{j}^{i}=\frac{1}{2}\left(x_{j}^{i}+x_{j}^{i-1}\right)
$$

where $i>2$ and $x_{j}^{i}$ shows the position of the $i$ th follower salp in the $j$ th dimension.

\section{Sequential steps for $S S A$}

i. The lower and upper bounds for all the search agents are initialized. The initialization process for different search agents is assigned randomly at the initial stage within their lower and upper bounds. Moreover, the total number of iterations is decided and then, the number of search agents to be used in the algorithm is decided; ii. At this stage, the objection function of the system is calculated. This function depends on the independent variables given by the user;

iii. If the fitness function value obtained in the present iteration is lower than the previous iteration value, then it can be assigned as the local best. Then, the salp swarm function starts its processing. Initially, the parameters of SSA are assigned a fixed value and as the iterations increase, the value of these parameters keeps on changing. By using SSA algorithm, the changed value of search agents must check their different constraints. If there is any violation, then their values are fixed in their boundary conditions;

iv. As the iteration changes, the values of these three parameters also change and the search agents collectively move towards the global optimum value (Eq. (14)). Following every iteration, the fitness value of the search agents also changes. The search agent that is nearest to the global optimum value has the highest fitness. In this way, the search agents will move in the search space and will explore the entire search space for the optimized value. Once the location of the optimized value is known to the search agent, then the phase of exploitation will begin. Now, instead of moving in the entire search space, the search agents will exploit the regions in which the results are promising. In this way, they tend to move towards the global optimum value (Eq. (15)). Once the iteration count is reached or the value of the cost function is obtained within the tolerance limit, the iteration is terminated. The result obtained at that time is considered to be the sub-global value (Eq. (16));

v. Once the final iteration count is reached, the algorithm is terminated and the search agents having the highest fitness are considered to be nearest to the global optimum value.

The flowchart of the SSA algorithm is shown in Figure 1 .

In this subsection, the steps to solve the ELD problem through the SSA implementation are explained. The detailed sequential steps for solving the ELD problem are explained below:

i. Initialization of various parameters takes place in the first step. Various variables like the lower bound, upper bound, total power demand $P_{D}$, etc. are initialized. The total number of generators is denoted by $m$ and total number of search agents is denoted by Popsize.

The search agent matrix is represented as follows:

$X=X_{i}=\left[X_{1}, X_{2}, X_{3}, \cdots, X_{\text {Popsize }}\right]$, 


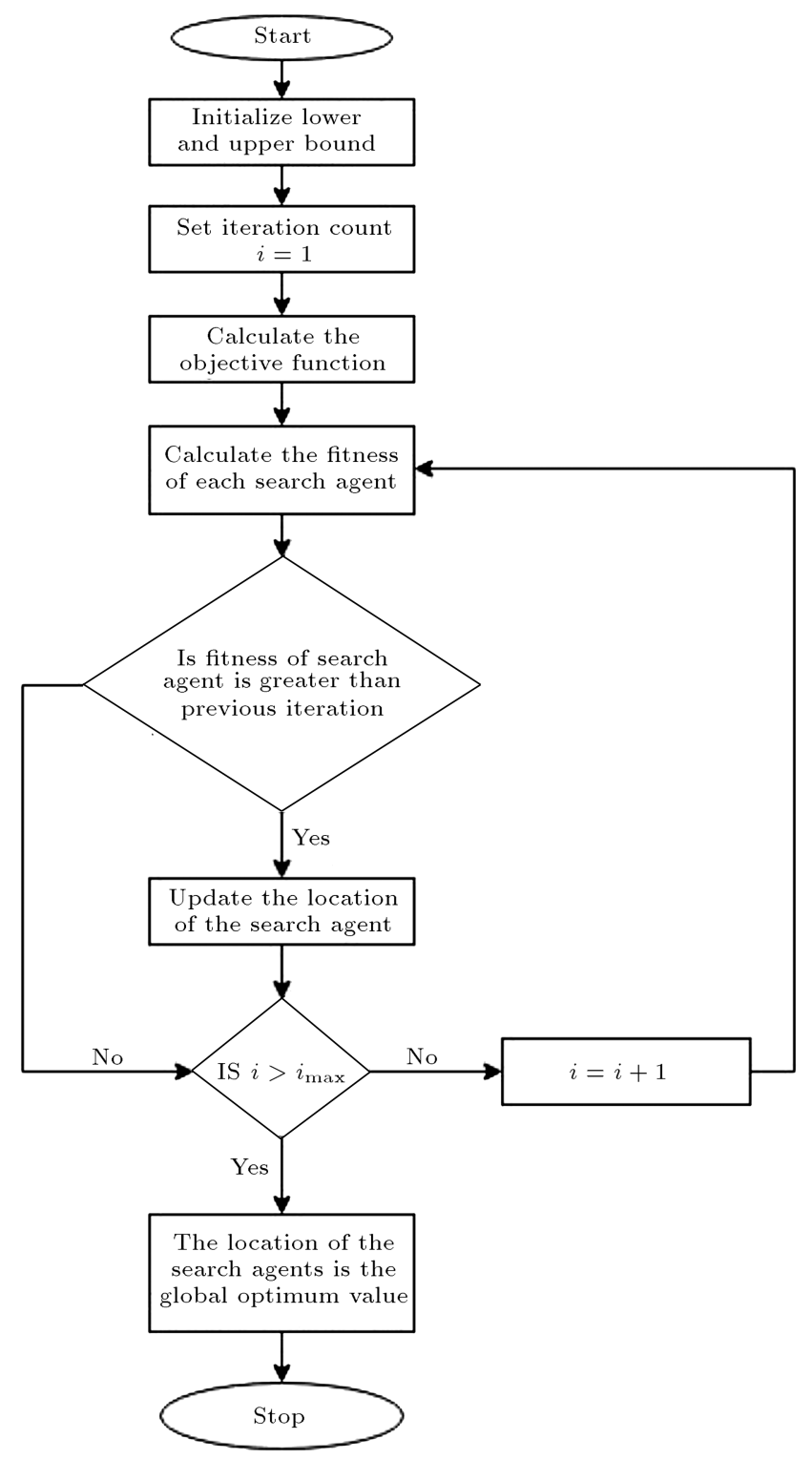

Figure 1. Flowchart of salp swarm algorithm.

where $i=1,2,3, \cdots$, Popsize. For ELD problem, the search agent matrix is assigned as active power generation and represented as follows:

$$
\begin{aligned}
{\left[X_{i j}\right] } & =\left[X_{i 1}, X_{i 2}, X_{i 3}, \cdots, X_{i m}\right] \\
& =\left[P_{i 1}, P_{i 2}, P_{i 3}, \cdots, P_{i m}\right]=\left[P_{i j}\right],
\end{aligned}
$$

where $m$ is the number of generators.

ii. Each of the elements of the search agent should follow Eqs. (3), (6), (7), (8), and (9). If various effects like the ramp rate limit and the prohibited operating zone are considered, then the equation should be satisfied based on Inequalities (6)-(9).

iii. For the ELD problem, the objective function is considered the fuel cost of power generation and it can be using Eq. (1) when quadratic fuel cost function is used and Eq. (2) when valve point loading effect is considered. This objective function serves as the base of the algorithm. The function needs to be minimized to reduce the cost of the power generation in the system. The objective function of fuel cost is calculated based on the power generation $\left(P_{i j}\right)$ through step (i).

iv. The main working mechanisms of the algorithm begin from Eq. (14). The values for the four main parameters of the algorithm are assigned to the concerned variables, i.e., $c_{1}$ to $c_{3}$. These values facilitate the movement of the search agent $\left(X_{i j}\right)$ (i.e., power generation $\left(P_{i j}\right)$ ) in the search space. By using Eqs. (13)-(15), the movement of search agents takes place in the search space.

v. Now, the new values of the power generations are obtained. These new values are checked for the constraints given in Inequalities $(3),(6),(7)$, (8), and (9). If various effects like the ramp rate limit and the prohibited operating zone are considered, then the equation should be satisfied based on Inequalities (6)-(9). If any value violates any of these constraints, then its upper or lower value is considered. Moreover, the slack value of power generation can be calculated based on Eqs. (11) and (12). If there are any violations of any Inequality Constraints (3), (6), (7), (8), and (9) which are valid for the slack generator, then repeat step (ii). This process continues until the ultimate set of the power generation matrix is formed.

vi. The new objective function of fuel cost can be calculated based on the newly generated power generation matrix.

vii. Now, the current objective values are compared with those obtained through the previous iterations. If the present objective value is less than the previous value, then the present value is treated as the best local optimized value; however, if the current value is not lower than the previous one, then the previous value remains in the same position of the newly generated value of the power generation matrix. Now, the objective function value obtained at the present iteration is compared to all other values obtained at different iterations and finally, the minimum value is made the global optimum value. This global optimum value is stored in a different memory location.

viii. Go to step (ii) for the next iteration. Terminate the process after reaching a predetermined value of the iteration count.

\section{Simulations and results}

To prove the effectiveness of the SSA, six sets of 
experiments were conducted and the final results were compared to various existing methods in a tabular manner as well as graphically.

The SSA algorithm was applied to four different test systems with varying degrees of complexity for verifying its effectiveness and feasibility. The program was written in MATLAB-2017B language and executed on a $1.7 \mathrm{GHz}$ Intel Core i3 personal computer with 4GB RAM. All the systems were re-simulated with the same configuration.

Test Case 1: Six generator units have been considered in Test Case 1, where the transmission losses have been taken into account. The total power demand is 1263 MW. Here, we have not considered valve point loading effect, ram-rate limit, or prohibited operating zone. The input data were taken from [45] and the system runs for 400 iterations. The number of search agents used is 50 in this case. In Test Case 1, the results of the SSA algorithm are compared with those of TLBO [45], CTLBO [45] and AIS [45] optimization techniques. According to the graph and the table, the minimum cost is first reached using the SSA algorithm and the rest of the optimization techniques take a minimum time compared to others. Table 1 shows that the minimum fuel cost for 6 generator units is $15377.8907 \$ / \mathrm{hr}$ obtained by the proposed algorithm, which is better than TLBO [45], CTLBO [45], and
AIS [45]. The minimum, maximum, and average fuel costs obtained after 50 trials are presented in Table 2. The convergence characteristics of SSA are shown in Figure 2. The net power delivered to the system is calculated as 1274.0128 MW. Hence, the accuracy of the result is $99.99 \%$ based on Eq. (4).

Test Case 2: Ten generator units have been considered in Test Case 2, where the transmission losses have been neglected. This test case incorporates multi fuel costs and valve point loading effect. Here, we have not assumed the ram-rate limit or the prohibited operating zone. The total power demand is $2700 \mathrm{MW}$.

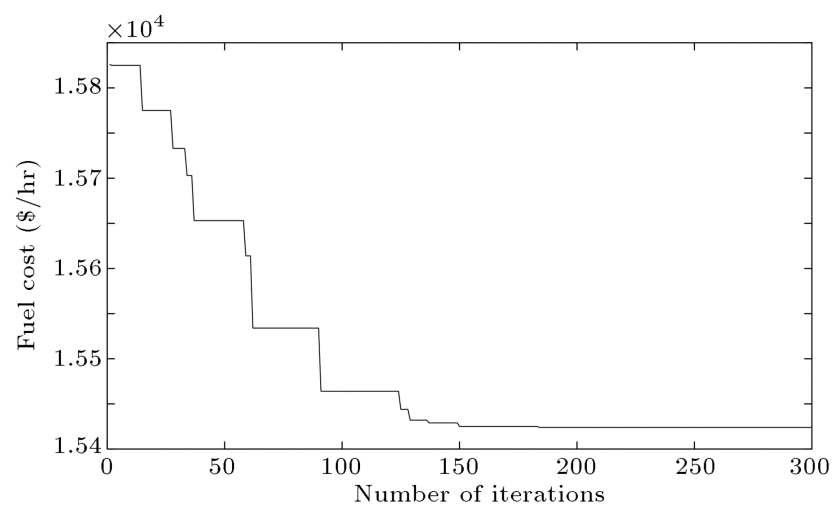

Figure 2. Convergence characteristic of SSA for 6 generator units.

Table 1. Optimum power output and fuel cost for SSA and other techniques comparison for the 6-unit test system.

\begin{tabular}{ccccccc}
\hline & \multicolumn{5}{c}{ Power Output (MW) } \\
\cline { 2 - 7 } Unit & SSA & TLBO [45] & CTLBO [45] & AIS [45] & QGSA[60] & IPSO-TVSC [61] \\
\hline$P_{1}$ & 442.9518 & 446.7270 & 449.4980 & 458.2904 & 263.9079 & 447.5840 \\
$P_{2}$ & 172.7533 & 173.4890 & 173.4810 & 168.0518 & 173.2418 & 173.2010 \\
$P_{3}$ & 257.3543 & 173.4890 & 264.9700 & 262.5175 & 263.9079 & 263.3310 \\
$P_{4}$ & 136.1425 & 138.8320 & 127.4610 & 139.0604 & 139.0529 & 138.8520 \\
$P_{5}$ & 162.5341 & 165.6500 & 173.8420 & 178.3936 & 165.6013 & 165.3280 \\
$P_{6}$ & 102.0713 & 86.9460 & 86.2390 & 69.3416 & 86.5357 & 87.1500 \\
Transmission loss (MW) & 11.0128 & 12.4180 & 12.4900 & 13.1997 & 12.4163 & 12.4460 \\
Power generated $(\mathrm{MW})$ & 1274.0128 & 1275.4180 & 1275.4900 & 1275.6550 & 1275.4163 & 1275.4460 \\
Fuel cost $(\$ / \mathrm{hr})$ & 15424.0734 & $15,442.5200$ & $15,441.6970$ & $15,448.0000$ & $15,442.6608$ & 15443.0630 \\
\hline
\end{tabular}

Table 2. Minimum maximum and average cost obtained by SSA and various optimization techniques for 6 generator units (50 trials).

\begin{tabular}{ccccccc}
\hline \multirow{2}{*}{ Methods } & \multicolumn{3}{c}{ Generation cost $(\$ / \mathbf{h r})$} & $\begin{array}{c}\text { No. of hits to } \\
\text { minimum } \\
\text { solution }\end{array}$ & $\begin{array}{c}\text { Standard } \\
\text { deviation }\end{array}$ \\
\cline { 2 - 5 } & Maximum & Minimum & Average & & \\
\hline SSA & 15427.0734 & 15424.0734 & 15424.2534 & 47 & 0.06 \\
TLBO [45] & 15450.3685 & 15442.5200 & 15445.8163 & 29 & 0.42 \\
CTLBO [45] & 15449.0236 & 15441.6970 & 15445.9464 & 21 & 0.58 \\
AIS [45] & NA $^{*}$ & 623.9588 & NA & NA & NA \\
QGSA [60] & $15,442.6630$ & $15,442.6608$ & $15,442.6614$ & NA & NA \\
IPSO-TVSC [61] & 155445.1140 & 15443.0630 & 15443.5820 & NA & NA \\
\hline
\end{tabular}

*NA: Not Available. 
Table 3. Optimum power output and fuel cost for SSA, and other techniques comparison for the 10-unit test system.

\begin{tabular}{|c|c|c|c|c|c|c|c|c|c|c|}
\hline \multirow[b]{2}{*}{ Unit } & \multicolumn{9}{|c|}{ Power Output (MW) } & \multirow[b]{2}{*}{$\begin{array}{c}\text { OKHA } \\
{[47]}\end{array}$} \\
\hline & $\begin{array}{l}\text { Fuel } \\
\text { type }\end{array}$ & SSA & $\begin{array}{l}\text { Fuel } \\
\text { type }\end{array}$ & $\begin{array}{c}\text { PSO-LRS } \\
{[47]}\end{array}$ & $\begin{array}{l}\text { Fuel } \\
\text { type }\end{array}$ & $\begin{array}{c}\text { APSO } \\
{[47]}\end{array}$ & $\begin{array}{l}\text { Fuel } \\
\text { type }\end{array}$ & $\begin{array}{c}\text { CBPSO-RVM } \\
{[47]}\end{array}$ & $\begin{array}{l}\text { Fuel } \\
\text { type }\end{array}$ & \\
\hline$P_{1}$ & 2 & 217.0407 & 2 & 219.0155 & 2 & 223.3377 & 2 & 219.2073 & 2 & 214.4684 \\
\hline$P_{2}$ & 1 & 211.8944 & 1 & 213.8901 & 1 & 212.1547 & 1 & 210.2203 & 1 & 208.9873 \\
\hline$P_{3}$ & 1 & 281.6792 & 1 & 283.7616 & 1 & 276.2203 & 1 & 278.5456 & 1 & 332.0575 \\
\hline$P_{4}$ & 3 & 238.2056 & 3 & 237.2687 & 3 & 239.4176 & 3 & 239.3704 & 3 & 238.1622 \\
\hline$P_{5}$ & 1 & 279.8321 & 1 & 286.0163 & 1 & 274.6411 & 1 & 276.412 & 1 & 269.2157 \\
\hline$P_{6}$ & 3 & 239.2547 & 3 & 239.3987 & 3 & 239.7953 & 3 & 240.5797 & 3 & 238.5653 \\
\hline$P_{7}$ & 1 & 290.2798 & 1 & 291.1767 & 1 & 285.5406 & 1 & 292.3267 & 1 & 280.6120 \\
\hline$P_{8}$ & 3 & 240.2228 & 3 & 241.4398 & 3 & 240.6270 & 3 & 237.7557 & 3 & 237.6241 \\
\hline$P_{9}$ & 3 & 425.5958 & 3 & 416.9721 & 3 & 429.3104 & 3 & 429.4008 & 3 & 413.8705 \\
\hline$P_{10}$ & 1 & 275.9942 & 1 & 271.0623 & 1 & 278.9553 & 1 & 276.1815 & 1 & 266.4366 \\
\hline $\begin{array}{l}\text { Fuel cost } \\
\qquad(\$ / \mathrm{hr})\end{array}$ & & 623.9170 & & 624.2297 & & 624.0145 & & 623.9588 & & $605.6449 *$ \\
\hline
\end{tabular}

*The precise fuel generation cost in [47] is $628.8264 \$ / \mathrm{hr}$ which is much higher than that reported in [47].

Table 4. Minimum, maximum, and average costs obtained by SSA, and various optimization techniques for 10 generator units (50 trials).

\begin{tabular}{ccccccc}
\hline & \multicolumn{2}{c}{ Generation cost $\mathbf{( \$ / h r )}$} & & $\begin{array}{c}\text { No. of hits to } \\
\text { minimum } \\
\text { solution }\end{array}$ & $\begin{array}{c}\text { Standard } \\
\text { deviation }\end{array}$ \\
\cline { 2 - 4 } Methods & Maximum & Minimum & Average & & \\
\hline SSA & 623.9170 & 623.9170 & 623.9170 & 50 & 0 \\
PSO-LRS [47] & 626.7210 & 624.2297 & 625.3756 & 27 & 0.46 \\
APSO [47] & 628.3947 & 624.0145 & 626.5550 & & 21 & 0.58 \\
CBPSO-RVM [47] & NA* $^{*}$ & 623.9588 & NA & NA & NA \\
\hline *NA: Not Available. & & & & &
\end{tabular}

The input data were taken from [46]. The number of search agents used is 50 in this case. In this test case, the results obtained from SSA algorithm are compared with those of PSO-LRS [47], APSO [47], CBPSO-RVM [47], and OKHA [47] optimization techniques to prove the effectiveness of SSA algorithm. In Table 3, the minimum fuel cost for 10 generator units is 623.9170 $\$ /$ hr obtained by the proposed algorithm, which outperforms PSO-LRS [47], APSO [47], CBPSO-RVM [47], and OKHA [47]. The minimum, maximum, and average fuel costs obtained after 50 trials are presented in Table 4. According to Table 4, the minimum cost is first reached by using the SSA algorithm and the rest of the optimization techniques take a minimum time compared to others. The convergence characteristic of SSA is shown in Figure 3. The net power delivered to the system is calculated as $2699.9999 \mathrm{MW}$. Hence, the accuracy of the result is $99.9999 \%$ based on Eq. (4) with transmission losses, which have been neglected. The fuel cost mentioned for OKHA [47] is 605.6449 $\$ /$ hr; however, based on the mentioned output power generation for each unit with consideration of the input data from [46], the actual fuel cost is calculated as $628.8264 \$ / \mathrm{hr}$, which is much higher than that obtained by SSA.

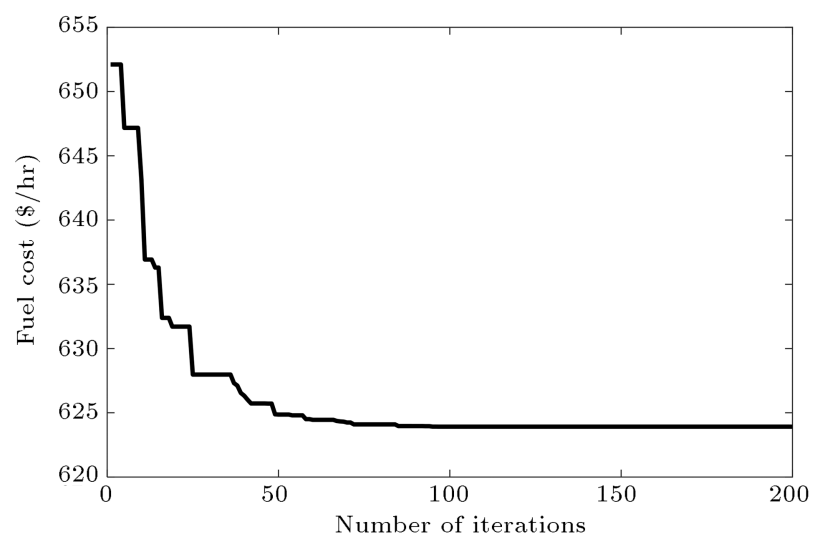

Figure 3. Convergence characteristic of SSA for 10 generator units.

Test Case 3: Thirteen generator units have been considered in Test Case 3, where the transmission losses have been considered. The total power demand is 2520 MW. The input data were taken from [48] and the system runs for 400 iterations. Here, we considered valve point loading and neglected ram-rate limit and prohibited operating zone. The number of search agents used is 50 in this case. In this test case, the results of the SSA algorithm are compared with those 
obtained by ORCCRO [49], SDE [50], and BSA [57] optimization techniques, as shown in Table 5. The fuel cost obtained using SSA is calculated to be 24512.6085 $\$ /$ hr. Based on Table 6 , the minimum cost is first reached by using the SSA algorithm and the rest of the optimization techniques take minimum time compared to others. The results obtained by the proposed algorithm are better than those of SDE [50], ORCCRO [49], and BSA [57]. The minimum, maximum, and average fuel costs obtained after 50 trials are presented in Table 6. The convergence characteristic of SSA is shown in Figure 4. The net power delivered to the system should be $2520 \mathrm{MW}$. Hence, the accuracy of the result is $100.00 \%$ based on Eq. (4).

Test Case 4: In this test case, 40 generator units with valve point loading have been considered. The test case has been split into two parts: In Test Case (a), transmission loss has been neglected, while in Test Case (b) it has been considered. For both cases,

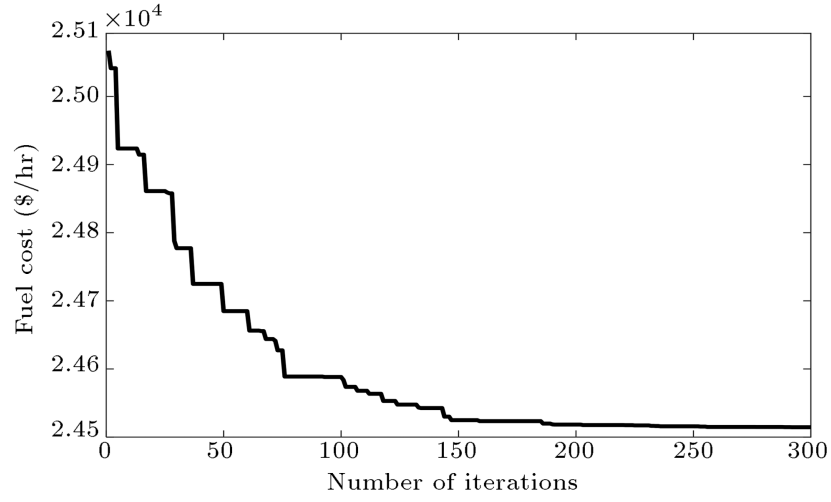

Figure 4. Convergence characteristic of SSA for 13 generator units.

prohibited operating zone and ram-rate limit have been neglected. The details of these two case studies have been given below. Here, this system can be of two types: that without transmission losses and the one with transmission losses considered.

Table 5. Optimum power output and fuel cost for SSA, and other techniques comparison for the 13-unit test system.

\begin{tabular}{ccccc}
\hline & \multicolumn{4}{c}{ Power output (MW) } \\
\cline { 2 - 5 } Unit & SSA & SDE $[\mathbf{4 1}]$ & ORCCRO [40] & BSA [48] \\
\hline$P_{1}$ & 628.3179 & 628.32 & 628.32 & 628.3158 \\
$P_{2}$ & 299.1992 & 299.20 & 299.20 & 299.1947 \\
$P_{3}$ & 297.4468 & 299.20 & 299.20 & 297.4764 \\
$P_{4}$ & 159.7327 & 159.73 & 159.73 & 159.7322 \\
$P_{5}$ & 159.7327 & 159.73 & 159.73 & 159.7330 \\
$P_{6}$ & 159.7328 & 159.73 & 159.73 & 159.7328 \\
$P_{7}$ & 159.7331 & 159.73 & 159.73 & 159.7318 \\
$P_{8}$ & 159.7325 & 159.73 & 159.73 & 159.7329 \\
$P_{9}$ & 159.7328 & 159.73 & 159.73 & 159.7286 \\
$P_{10}$ & 77.3995 & 77.40 & 77.40 & 77.3945 \\
$P_{11}$ & 114.7993 & 113.12 & 112.14 & 114.7992 \\
$P_{12}$ & 92.3997 & 92.40 & 92.40 & 92.3962 \\
$P_{13}$ & 92.4000 & 92.40 & 92.40 & 92.3919 \\
Power generation $(\mathrm{MW})$ & $\mathbf{2 5 5 9 . 8 0 0 0}$ & 2560.4300 & 2559.43 & 2560.3641 \\
Transmission loss $(\mathrm{MW})$ & $\mathbf{3 9 . 8 0 0 0}$ & 40.43 & 39.43 & 39.8006 \\
Fuel cost $(\$ / \mathrm{hr})$ & $\mathbf{2 4 5 1 2 . 6 0 8 5}$ & 24514.88 & 24513.91 & 24512.6654 \\
\hline
\end{tabular}

Table 6. Minimum, maximum, and average costs obtained by SSA and various optimization techniques for 13 generator units (50 trials).

\begin{tabular}{ccccccc}
\hline & \multicolumn{3}{c}{ Generation cost $(\$ / \mathbf{h r})$} & $\begin{array}{c}\text { No. of hits to } \\
\text { minimum } \\
\text { solution }\end{array}$ & $\begin{array}{c}\text { Standard } \\
\text { deviation }\end{array}$ \\
\cline { 2 - 4 } Methods & Maximum & Minimum & Average & & \\
\hline SSA & 24512.61 & 24512.61 & 24512.61 & 50 & 0 \\
ORCCRO [49] & 24518.56 & 24513.91 & 24515.72 & 27 & 0.46 \\
SDE [50] & 24519.74 & 24514.88 & 24516.23 & 21 & 0.58 \\
BBO [49] & NA $^{*}$ & 24519.69 & NA & NA & NA \\
DE/BBO [49] & 24522.45 & NA & 24519.58 & NA & NA \\
\hline
\end{tabular}

*NA: Not Available. 
Table 7. Optimum power output and fuel cost for SSA and other techniques comparison for the 40-unit test system.

\begin{tabular}{|c|c|c|c|}
\hline \multirow[b]{2}{*}{ Unit } & \multicolumn{3}{|c|}{ Power output (MW) } \\
\hline & SSA & EMA [51] & QPSO [51] \\
\hline$P_{1}$ & 110.7998 & 110.7998 & 111.2000 \\
\hline$P_{2}$ & 110.7998 & 110.7998 & 111.7000 \\
\hline$P_{3}$ & 97.3999 & 97.3999 & 97.4000 \\
\hline$P_{4}$ & 179.7331 & 179.7331 & 179.7300 \\
\hline$P_{5}$ & 87.7998 & 87.7999 & 90.1400 \\
\hline$P_{6}$ & 139.9999 & 140.0000 & 140.0000 \\
\hline$P_{7}$ & 259.5996 & 259.5996 & 259.6000 \\
\hline$P_{8}$ & 284.5996 & 284.5996 & 284.8000 \\
\hline$P_{9}$ & 284.5996 & 284.5996 & 284.8400 \\
\hline$P_{10}$ & 130.0000 & 130.0000 & 130.0000 \\
\hline$P_{11}$ & 94.0000 & 94.0000 & 168.8000 \\
\hline$P_{12}$ & 94.0000 & 94.0000 & 168.8000 \\
\hline$P_{13}$ & 214.7597 & 214.7598 & 214.7600 \\
\hline$P_{14}$ & 394.2793 & 394.2793 & 304.5300 \\
\hline$P_{15}$ & 394.2793 & 394.2793 & 394.2800 \\
\hline$P_{16}$ & 394.2793 & 394.2793 & 394.2800 \\
\hline$P_{17}$ & 489.2793 & 489.2793 & 489.2800 \\
\hline$P_{18}$ & 489.2793 & 489.2793 & 489.2800 \\
\hline$P_{19}$ & 511.2793 & 511.2793 & 511.2800 \\
\hline$P_{20}$ & 511.2794 & 511.2793 & 511.2800 \\
\hline$P_{21}$ & 523.2793 & 523.2793 & 523.2800 \\
\hline$P_{22}$ & 523.2793 & 523.2793 & 523.2800 \\
\hline$P_{23}$ & 523.2793 & 523.2793 & 523.2900 \\
\hline$P_{24}$ & 523.2793 & 523.2793 & 523.2800 \\
\hline$P_{25}$ & 523.2793 & 523.2793 & 523.2900 \\
\hline$P_{26}$ & 523.2793 & 523.2793 & 523.2800 \\
\hline$P_{27}$ & 10.0000 & 10.0000 & 10.0100 \\
\hline$P_{28}$ & 10.0000 & 10.0000 & 10.0100 \\
\hline$P_{29}$ & 10.0000 & 10.0000 & 10.0000 \\
\hline$P_{30}$ & 87.7999 & 87.7999 & 88.4700 \\
\hline$P_{31}$ & 189.9999 & 190.0000 & 190.0000 \\
\hline$P_{32}$ & 189.9999 & 190.0000 & 190.0000 \\
\hline$P_{33}$ & 190.0000 & 190.0000 & 190.0000 \\
\hline$P_{34}$ & 164.7998 & 164.7998 & 164.9100 \\
\hline$P_{35}$ & 199.9999 & 200.000 & 165.3600 \\
\hline$P_{36}$ & 194.3976 & 194.3977 & 167.1900 \\
\hline$P_{37}$ & 109.9999 & 110.0000 & 110.0000 \\
\hline$P_{38}$ & 109.9999 & 110.0000 & 107.0100 \\
\hline$P_{39}$ & 109.9999 & 110.0000 & 110.0000 \\
\hline$P_{40}$ & 511.2794 & 511.2793 & 511.3600 \\
\hline Fuel cost $(\$ / \mathrm{hr})$. & 121412.5347 & 121412.5355 & 121448.2100 \\
\hline
\end{tabular}

Test Case 4(a): In this case, 40 generator units with valve point are considered. Transmission losses are neglected. The input data were taken from [51]. The total load demand is $10500 \mathrm{MW}$. In Test Case $4(\mathrm{a})$, the results of the SSA algorithm are compared with those of EMA [51] and QPSO [51] optimization techniques. According to Table 7 , the minimum cost is first reached by using the SSA algorithm and the rest of the optimization techniques take a longer time to complete. As shown in Table 7, the minimum fuel cost for 40 generator units is $121412.5347 \$ / \mathrm{hr}$ obtained by the proposed algorithm, which outperforms EMA [51] and QPSO [51]. The minimum, maximum, and average fuel costs obtained after 50 trials are presented 
Table 8. Minimum, maximum, and average cost obtained by SSA and various optimization techniques for 40 generator units (50 trials).

\begin{tabular}{|c|c|c|c|c|c|}
\hline \multirow[t]{2}{*}{ Methods } & \multicolumn{3}{|c|}{ Generation cost $(\$ / h r)$} & \multirow{2}{*}{$\begin{array}{l}\text { No. of hits to } \\
\text { minimum } \\
\text { solution }\end{array}$} & \multirow{2}{*}{$\begin{array}{l}\text { Standard } \\
\text { deviation }\end{array}$} \\
\hline & Maximum & Minimum & Average & & \\
\hline $\mathrm{SSA}$ & 121415.2584 & 121412.5347 & 121413.0794 & 40 & 0.20 \\
\hline EMA $[51]$ & 121416.2031 & 121412.5355 & 121414.6617 & 21 & 0.58 \\
\hline QPSO $[51]$ & 121455.9510 & 121448.2100 & 121453.6287 & 15 & 0.70 \\
\hline
\end{tabular}

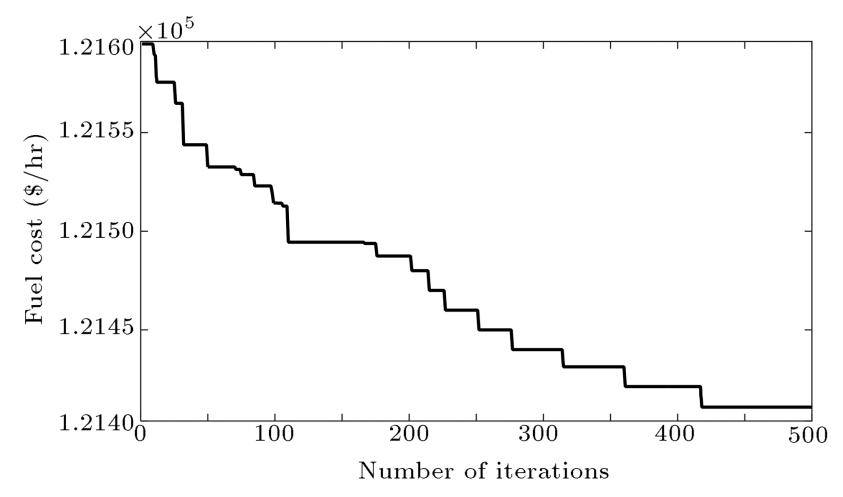

Figure 5. Convergence characteristic of SSA for 40 generator units.

in Table 8. The convergence characteristic of SSA is displayed in Figure 5. The net power delivered to the system is calculated as $10500 \mathrm{MW}$. Hence, the accuracy of the result is $100.00 \%$ based on Eq. (4) with transmission losses neglected.

Test Case 4(b): In this case, 40 generator units have been considered and their transmission losses have been taken into consideration. The total power demand is $10500 \mathrm{MW}$. The input data was taken from [52] and the system runs for 400 iterations. Fifty search agents are used in this case. Only valve-point loading effect is considered as a constraint for this test case. The comparison of the optimum fuel cost obtained by different optimization techniques is given in Table 9 . Table 10 shows the minimum, maximum, and average fuel costs obtained by various optimization techniques after 50 trials. The convergence characteristic is shown in Figure 6. The minimum fuel cost obtained using SSA is calculated as $136653.0219 \$ / \mathrm{hr}$. Based on the tabular data, it is clear that the minimum fuel cost is obtained by SSA which performs better than other techniques like GAAPI [49], DE/BBO [49], SDE [50], and BBO [49]. The net power delivered to the system is calculated as $10500 \mathrm{MW}$. Hence, the accuracy of the result is $100.00 \%$ based on Eq. (4).

Test Case 5: To investigate the efficiency of SSA in a large power system, experiments are conducted on

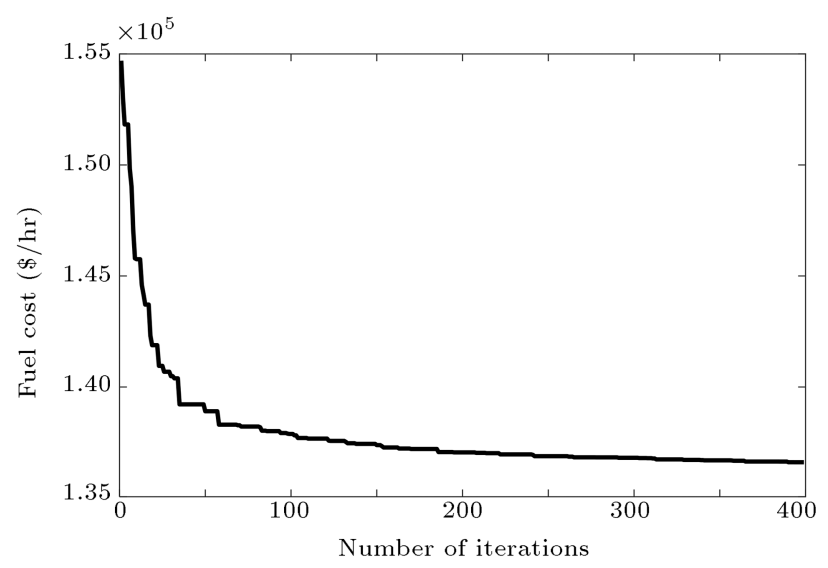

Figure 6. Convergence characteristic of SSA for 40 generating units.

the Korean power system. The input data were taken from [58]. This test system is a fossil fuel-based power system, composed of forty thermal generating units, fifty-one gas units, twenty nuclear units, and twentynine oil units. Out of 140 units, 6 thermal units, 4 gas units, and 2 oil units have non-convex fuel cost function addressing valve loading effects. The total load demand is 49342 MW. A large and complicated test system of 140 generating units has been considered here with valve point loading effects, ramp rate limits, and prohibited operating zones. The system is made to run for 1000 iterations. Fifty search agents are used in this case. Since the cost function of each generating unit is considered as the second-order polynomial, the global optimum solution can be obtained using the mathematical programming techniques. Table 11 shows the power generation of each of the 140 generators using the SSA. The total fuel cost obtained by SSA is calculated as $1658384.8872 \$ / \mathrm{hr}$. Table 12 compares the minimum, maximum, and average fuel costs obtained using various optimization techniques after 50 trials. Figure 7 shows the convergence characteristic of SSA. The results in Table 11 prove that the minimum fuel cost is obtained using SSA which is much better than other algorithms. The net power delivered to the system is calculated as $49342 \mathrm{MW}$. Hence, the accuracy of the result is $100.00 \%$ based on Eq. (4). 
Table 9. Optimum power output and fuel cost for SSA and other techniques comparison for the 40-unit test system.

\begin{tabular}{|c|c|c|c|c|c|}
\hline \multirow{2}{*}{ Unit } & \multicolumn{5}{|c|}{ Power output (MW) } \\
\hline & SSA & GAAPI [49] & $\mathrm{DE} / \mathrm{BBO}[49]$ & SDE [50] & BBO [49] \\
\hline$P_{1}$ & 113.8585 & 114.0000 & 111.0400 & 110.0600 & 112.5400 \\
\hline$P_{2}$ & 114.0000 & 114.0000 & 113.7100 & 112.4100 & 113.2200 \\
\hline$P_{3}$ & 119.3004 & 120.0000 & 118.6400 & 120.0000 & 119.5100 \\
\hline$P_{4}$ & 183.3369 & 190.0000 & 189.4900 & 188.7200 & 188.3700 \\
\hline$P_{5}$ & 91.7652 & 97.0000 & 86.3200 & 85.9100 & 90.4100 \\
\hline$P_{6}$ & 139.9816 & 140.0000 & 139.8800 & 140.0000 & 139.0500 \\
\hline$P_{7}$ & 299.5148 & 300.0000 & 299.8600 & 250.1900 & 294.9700 \\
\hline$P_{8}$ & 299.1356 & 300.0000 & 285.4200 & 290.6800 & 299.1800 \\
\hline$P_{9}$ & 297.6808 & 300.0000 & 296.2900 & 300.0000 & 296.4600 \\
\hline$P_{10}$ & 279.1599 & 205.2500 & 285.0700 & 282.0100 & 279.8900 \\
\hline$P_{11}$ & 171.4666 & 226.300 & 164.6900 & 180.8200 & 160.1500 \\
\hline$P_{12}$ & 94.4916 & 204.7200 & 94.0000 & 168.7400 & 96.7400 \\
\hline$P_{13}$ & 485.0345 & 346.4800 & 486.3000 & 469.9600 & 484.0400 \\
\hline$P_{14}$ & 482.8777 & 434.3200 & 480.7000 & 484.1700 & 483.3200 \\
\hline$P_{15}$ & 484.0869 & 431.3400 & 480.6600 & 487.7300 & 483.7700 \\
\hline$P_{16}$ & 484.9795 & 440.2200 & 485.0500 & 482.3000 & 483.3000 \\
\hline$P_{17}$ & 489.6806 & 500.0000 & 487.9400 & 499.6400 & 490.8300 \\
\hline$P_{18}$ & 488.7718 & 500.0000 & 491.0900 & 411.3200 & 492.1900 \\
\hline$P_{19}$ & 515.9524 & 550.0000 & 511.7900 & 510.4700 & 511.2800 \\
\hline$P_{20}$ & 511.6585 & 550.0000 & 544.8900 & 542.0400 & 521.5500 \\
\hline$P_{21}$ & 532.3453 & 550.0000 & 528.9200 & 544.8100 & 526.4200 \\
\hline$P_{22}$ & 549.9726 & 550.0000 & 540.5800 & 550.0000 & 538.3000 \\
\hline$P_{23}$ & 523.9532 & 550.0000 & 524.9800 & 550.0000 & 534.7400 \\
\hline$P_{24}$ & 527.3965 & 550.0000 & 524.1200 & 528.1600 & 521.2000 \\
\hline$P_{25}$ & 523.3733 & 550.0000 & 534.4900 & 524.1600 & 526.1400 \\
\hline$P_{26}$ & 527.6279 & 550.0000 & 529.1500 & 539.1000 & 544.4300 \\
\hline$P_{27}$ & 10.0009 & 11.4400 & 10.5100 & 10.0000 & 11.5100 \\
\hline$P_{28}$ & 11.1190 & 11.5600 & 10.0000 & 10.3700 & 10.2100 \\
\hline$P_{29}$ & 10.1184 & 11.4200 & 10.0000 & 10.0000 & 10.7100 \\
\hline$P_{30}$ & 86.9830 & 97.0000 & 90.0600 & 96.1000 & 88.2800 \\
\hline$P_{31}$ & 189.9885 & 190.0000 & 189.8200 & 185.3300 & 189.8400 \\
\hline$P_{32}$ & 189.9150 & 190.0000 & 187.6900 & 189.5400 & 189.9400 \\
\hline$P_{33}$ & 189.9535 & 190.0000 & 189.9700 & 189.9600 & 189.1300 \\
\hline$P_{34}$ & 199.9110 & 200.0000 & 199.8300 & 199.9000 & 198.0700 \\
\hline$P_{35}$ & 197.9306 & 200.0000 & 199.9300 & 196.2500 & 199.9200 \\
\hline$P_{36}$ & 165.3294 & 200.0000 & 163.0300 & 185.8500 & 194.3500 \\
\hline$P_{37}$ & 109.4111 & 110.0000 & 109.8500 & 109.7200 & 109.4300 \\
\hline$P_{38}$ & 109.9582 & 110.0000 & 109.2600 & 110.0000 & 109.5600 \\
\hline$P_{39}$ & 109.9271 & 110.0000 & 109.6000 & 95.7100 & 109.6200 \\
\hline$P_{40}$ & 547.6016 & 550.0000 & 543.2300 & 532.4700 & 527.8200 \\
\hline Fuel cost $(\$ / \mathrm{hr})$ & 136653.0219 & 139864.96 & 136950.77 & 138157.46 & 137026.82 \\
\hline Power generation (MW) & 11459.5499 & 11545.0600 & 11457.8300 & 11474.4300 & 11470.0000 \\
\hline Transmission loss (MW) & 959.5500 & 1045.0600 & 957.8300 & 974.4300 & 970.3700 \\
\hline
\end{tabular}


Table 10. Minimum, maximum, and average fuel costs obtained by SSA and various optimization techniques for 40 generator units (50 trials).

\begin{tabular}{ccccccc}
\hline & \multicolumn{3}{c}{ Generation cost $(\$ / \mathbf{h r})$} & $\begin{array}{c}\text { No. of hits to } \\
\text { minimum } \\
\text { solution }\end{array}$ & $\begin{array}{c}\text { Standard } \\
\text { deviation }\end{array}$ \\
\cline { 2 - 5 } Methods & Maximum & Minimum & Average & & \\
\hline SSA & 136653.10 & 136653.02 & 136653.02 & 48 & 0.04 \\
BBO [49] & 137587.82 & 137026.82 & 137116.58 & 41 & 0.18 \\
DE/BBO [49] & 137150.77 & 136950.77 & 136966.77 & 45 & 0.10 \\
ORCCRO [49] & 136855.19 & 136845.35 & 136848.16 & 43 & 0.14 \\
\hline
\end{tabular}

Table 11. Optimum power output and fuel cost for SSA for the 140-unit test system.

\begin{tabular}{|c|c|c|c|c|c|c|c|}
\hline Unit & $\begin{array}{c}\text { Power } \\
\text { output (MW) }\end{array}$ & Unit & $\begin{array}{c}\text { Power } \\
\text { output (MW) }\end{array}$ & Unit & $\begin{array}{c}\text { Power } \\
\text { output (MW) }\end{array}$ & Unit & $\begin{array}{c}\text { Power } \\
\text { output (MW) }\end{array}$ \\
\hline$P_{1}$ & 110.8395 & $P_{36}$ & 499.9997 & $P_{71}$ & 140.7389 & $P_{106}$ & 880.9000 \\
\hline$P_{2}$ & 163.9999 & $P_{37}$ & 240.9999 & $P_{72}$ & 388.4824 & $P_{107}$ & 873.6998 \\
\hline$P_{3}$ & 189.9518 & $P_{38}$ & 240.9424 & $P_{73}$ & 230.9036 & $P_{108}$ & 877.4000 \\
\hline$P_{4}$ & 189.9612 & $P_{39}$ & 773.9925 & $P_{74}$ & 271.6243 & $P_{109}$ & 871.6999 \\
\hline$P_{5}$ & 168.3794 & $P_{40}$ & 768.9999 & $P_{75}$ & 175.9105 & $P_{110}$ & 864.7967 \\
\hline$P_{6}$ & 186.3858 & $P_{41}$ & 3.161799 & $P_{76}$ & 293.5256 & $P_{111}$ & 881.9998 \\
\hline$P_{7}$ & 489.9999 & $P_{42}$ & 3.072809 & $P_{77}$ & 306.7155 & $P_{112}$ & 94.20313 \\
\hline$P_{8}$ & 489.9997 & $P_{43}$ & 239.2171 & $P_{78}$ & 385.5398 & $P_{113}$ & 95.06407 \\
\hline$P_{9}$ & 496.0000 & $P_{44}$ & 249.8248 & $P_{79}$ & 530.9998 & $P_{114}$ & 94.32693 \\
\hline$P_{10}$ & 496.0000 & $P_{45}$ & 247.436 & $P_{80}$ & 530.9998 & $P_{115}$ & 244.0719 \\
\hline$P_{11}$ & 495.9984 & $P_{46}$ & 249.2271 & $P_{81}$ & 542.0000 & $P_{116}$ & 245.6768 \\
\hline$P_{12}$ & 495.9999 & $P_{47}$ & 246.1245 & $P_{82}$ & 56.66217 & $P_{117}$ & 245.6193 \\
\hline$P_{13}$ & 505.9871 & $P_{48}$ & 247.8030 & $P_{83}$ & 115.1015 & $P_{118}$ & 96.84149 \\
\hline$P_{14}$ & 508.9965 & $P_{49}$ & 246.1036 & $P_{84}$ & 115.0754 & $P_{119}$ & 95.7353 \\
\hline$P_{15}$ & 505.9998 & $P_{50}$ & 246.5329 & $P_{85}$ & 115.9195 & $P_{120}$ & 116.5415 \\
\hline$P_{16}$ & 504.9999 & $P_{51}$ & 165.1967 & $P_{86}$ & 207.117 & $P_{121}$ & 175.1441 \\
\hline$P_{17}$ & 505.9566 & $P_{52}$ & 165.8992 & $P_{87}$ & 207.2333 & $P_{122}$ & 3.6211 \\
\hline$P_{18}$ & 505.9948 & $P_{53}$ & 185.7631 & $P_{88}$ & 176.4165 & $P_{123}$ & 4.0487 \\
\hline$P_{19}$ & 505.0000 & $P_{54}$ & 165.0393 & $P_{89}$ & 175.7241 & $P_{124}$ & 15.4299 \\
\hline$P_{20}$ & 504.9951 & $P_{55}$ & 180.1148 & $P_{90}$ & 177.7537 & $P_{125}$ & 9.6570 \\
\hline$P_{21}$ & 504.9971 & $P_{56}$ & 180.9737 & $P_{91}$ & 180.4744 & $P_{126}$ & 13.0826 \\
\hline$P_{22}$ & 504.9874 & $P_{57}$ & 112.9304 & $P_{92}$ & 575.3998 & $P_{127}$ & 10.0005 \\
\hline$P_{23}$ & 504.9936 & $P_{58}$ & 199.5520 & $P_{93}$ & 547.4997 & $P_{128}$ & 112.0987 \\
\hline$P_{24}$ & 504.9997 & $P_{59}$ & 311.9997 & $P_{94}$ & 836.7998 & $P_{129}$ & 4.7148 \\
\hline$P_{25}$ & 537.0000 & $P_{60}$ & 299.2522 & $P_{95}$ & 837.4999 & $P_{130}$ & 5.0210 \\
\hline$P_{26}$ & 536.9998 & $P_{61}$ & 163.5181 & $P_{96}$ & 681.9973 & $P_{131}$ & 5.0062 \\
\hline$P_{27}$ & 548.9997 & $P_{62}$ & 99.08827 & $P_{97}$ & 719.9999 & $P_{132}$ & 50.1757 \\
\hline$P_{28}$ & 548.9996 & $P_{63}$ & 468.563 & $P_{98}$ & 717.9918 & $P_{133}$ & 5.0813 \\
\hline$P_{29}$ & 500.9999 & $P_{64}$ & 510.7641 & $P_{99}$ & 719.9925 & $P_{134}$ & 42.0132 \\
\hline$P_{30}$ & 498.9999 & $P_{65}$ & 489.9999 & $P_{100}$ & 963.9999 & $P_{135}$ & 42.0579 \\
\hline$P_{31}$ & 505.9997 & $P_{66}$ & 201.0382 & $P_{101}$ & 957.9999 & $P_{136}$ & 41.1626 \\
\hline$P_{32}$ & 505.9910 & $P_{67}$ & 488.1348 & $P_{102}$ & 947.8997 & $P_{137}$ & 17.0139 \\
\hline$P_{33}$ & 505.7959 & $P_{68}$ & 485.3448 & $P_{103}$ & 933.9998 & $P_{138}$ & 7.0044 \\
\hline$P_{34}$ & 505.9998 & $P_{69}$ & 132.4697 & $P_{104}$ & 934.9996 & $P_{139}$ & 7.0202 \\
\hline$P_{35}$ & 500.0000 & $P_{70}$ & 338.9781 & $P_{105}$ & 876.4997 & $P_{140}$ & 31.3066 \\
\hline
\end{tabular}


Table 12. Minimum, maximum, and average fuel cost obtained by SSA and various optimization techniques for 140 generator units (50 trials).

\begin{tabular}{ccccccc}
\hline \multirow{2}{*}{ Methods } & \multicolumn{3}{c}{ Generation cost $(\$ /$ hr $)$} & $\begin{array}{c}\text { No. of hits to } \\
\text { minimum } \\
\text { solution }\end{array}$ & $\begin{array}{c}\text { Standard } \\
\text { deviation }\end{array}$ \\
\cline { 2 - 4 } & Maximum & Minimum & Average & & \\
\hline SSA & 1658386.57 & 1658384.88 & 1658384.25 & 45 & 0.10 \\
BBO [49] & 1669536.35 & 1665478.25 & 1667548.32 & NA & NA \\
DE/BBO [49] & 1662349.58 & 1660215.65 & 1661257.35 & NA & NA \\
ORCCRO [49] & 1659823.97 & 1659654.83 & 1659725.96 & 42 & 0.16 \\
\hline
\end{tabular}

Table 13. Effect of various parameters on the performance of SSA.

\begin{tabular}{cccc}
\hline $\boldsymbol{c}_{\boldsymbol{1}}$ & $\boldsymbol{c}_{\boldsymbol{2}}$ & $\boldsymbol{c}_{\boldsymbol{3}}$ & Fuel cost $(\$ / \mathbf{h r})$ \\
\hline 0.16 & 0.41 & 0.14 & 1658479.1876 \\
0.68 & 0.65 & 0.15 & 1658455.6489 \\
0.47 & 0.87 & 0.62 & 1658438.3245 \\
0.57 & 0.54 & 0.25 & 1658420.9452 \\
0.55 & 0.65 & 0.34 & 1658397.3249 \\
0.7886 & 0.4082 & 0.3452 & 1658384.8872 \\
0.42 & 0.26 & 0.95 & 1658399.5475 \\
0.94 & 0.32 & 0.84 & 1658456.3225 \\
0.21 & 0.41 & 0.25 & 1658472.2587 \\
0.78 & 0.52 & 0.41 & 1658501.3654 \\
\hline
\end{tabular}

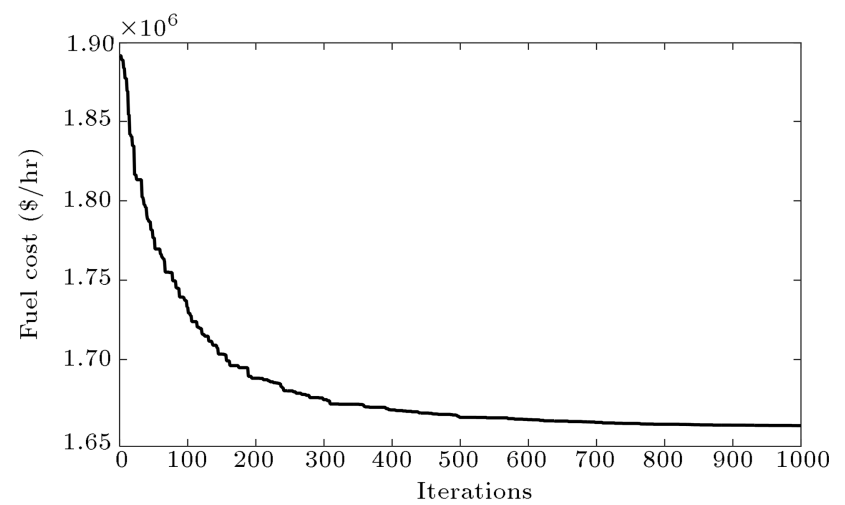

Figure 7. Decreasing cost for 140 generator units using SSA.

\subsection{Tuning of parameters for the $S S A$}

To obtain the optimized solution with the use ofSSA, it is imperative to obtain the proper values for parameters $c_{1}, c_{2}$, and $c_{3}$. Tuning of these parameters is essential to obtaining an optimized solution. Different values of these parameters give different fuel costs. For one single value of one parameter, other parameters should be changed for all possible combinations. For the single value of $c_{1}$, different combinations of $c_{2}$ and $c_{3}$ have been made to obtain the minimum fuel cost. The optimum fuel cost obtained for the 140-unit test system with all parameters including $c_{1}=0.7886, c_{2}=0.4082$, and $c_{3}=0.3452$ is $1658384.8872 \$ / \mathrm{hr}$, as shown in Table 13 . However, the optimum value of fuel cost obtained for other test systems is also consistent with the same values of all the parameters. Presenting all these results for all test systems in a table takes much space which has made us overlook the details of the tuning procedure. A brief result of the most complex 140-unit generator system out of five test systems is shown in Table 13.

Also, using a large number of search agents or few search agents for screening the search space does not ensure achieving the optimized solution. Therefore, a specific number of search agents only help obtain the optimized solution. For each search agent, trials have been run. The output obtained after using various search agents is shown in Table 14. Out of these trials, 50 search agents achieved the optimized fuel cost. For other search agents, no significant improvement in the fuel cost was observed. Moreover, the simulation time duration is definitely prolonged in the case of more than 50 search agents.

The optimum values of the tuned parameters are $P_{\text {size }}=50, c_{1}=0.7886, c_{2}=0.4082$, and $c_{3}=0.3452$. 
Table 14. Effect of the number of search agents on the 140-unit generator system.

\begin{tabular}{cccccc}
\hline $\begin{array}{c}\text { Number of } \\
\text { search agents }\end{array}$ & $\begin{array}{c}\text { No. of hits } \\
\text { to best solution }\end{array}$ & $\begin{array}{c}\text { Simulation } \\
\text { time }(\mathbf{s})\end{array}$ & $\begin{array}{c}\text { Max. cost } \\
(\$ \mathbf{h r})\end{array}$ & $\begin{array}{c}\text { Min. cost } \\
(\$ \mathbf{h r})\end{array}$ & $\begin{array}{c}\text { Average cost } \\
(\$ / \mathbf{h r})\end{array}$ \\
\hline 20 & 33 & 48.213 & 1658406.547 & 1658399.254 & 1658401.879 \\
50 & 45 & 50.42 & 1658386.570 & 1658384.880 & 1658384.250 \\
100 & 28 & 54.25 & 1658416.235 & 1658406.325 & 1658410.884 \\
150 & 18 & 57.247 & 1658428.625 & 1658412.658 & 1658422.558 \\
200 & 12 & 62.46 & 1658468.235 & 1658435.328 & 1658460.995 \\
\hline
\end{tabular}

\subsection{Simulation Time Comparison}

In this section, authors have created a table to compare the simulation time durations of the SSA algorithm with those of all the other algorithms for all the five different test cases. The authors understand that it is not possible to compare the simulation times as different authors have used different computer configurations. However, this table only gives an indication of the superiority of SSA with the same computer configurations. The programs have been written in MATLAB-2017B language and executed using a personal computer featuring $1.7 \mathrm{GHz}$ Intel core i3 and 4 GB RAM. All the systems are re-simulated with the same configuration.

\subsection{Comparative study}

Quality of Solution. Tables 1, 3, 5, 7, 9, and 11 show that the fuel cost obtained by the SSA is the least among other optimization techniques. The cost obtained by SSA is quite affordable compared to the costs obtained by many previously developed algorithms. For example, in Test Case 1, the minimum fuel cost of the SSA is $24512.6085 \$ / \mathrm{hr}$ which is less than the minimum fuel cost obtained by SDE and ORCCRO. The comparison was made by neglecting the transmission losses as well as taking the transmission losses into account. Thus, it is clear that the quality of the solution is the best when SSA is applied.

Robustness. The robustness of any optimization algorithm cannot be judged by only running the algorithm for a single time. A number of trials should be conducted to prove the robustness of any optimisation technique. According to Tables 4 and 6, SSA achieves the optimal solution for all the 50 trials in various test cases. According to Tables 2, 8, 10, and 12, it can be said that SSA gives the minimum fuel cost for the maximum number of trials as compared to other optimization techniques. This proves that the efficiency of the SSA is very high and SSA is superior to other optimization techniques in terms of performance.
This proves that the algorithm performs consistently well when it is compared to other algorithms.

Computational efficiency. The efficiency of any optimization technique is determined by the time the technique takes to reach the global optimal solution. According to Table 15, the computational time taken for one single iteration is the least for the SSA among other previously developed optimization techniques. Thus, the SSA achieves global optimal results in the least computational time.

\section{Conclusion}

A new algorithm called Salp Swarm Algorithm was proposed to solve ELD problem. To prove the efficiency of the SSA, five test systems of different kinds of thermal power plants were considered in which the main objective was the net fuel cost reduction. This objective was obtained by SSA, as shown in Tables 1, 3, $5,7,9$, and 11 . The comparison between the proposed technique and other techniques is also shown in these tables. The average, minimum, and maximum values obtained for different optimization techniques in various test systems within a particular number of trials were also considered important and minimized for any optimization technique. The authors managed to prove the effectiveness of SSA compared to other algorithm with consideration of the aforementioned components in Tables 2, 4, 6, 8, 10, and 12. Given that simulation time was also an important object in soft computing techniques, this study considered it for the same test system with the other efficient optimization techniques. The authors considered the simulation time for the above-discussed test systems and successfully proved that SSA took the minimum computational time. This was shown, as given in Table 15. The results proved that SSA was consistent, feasible, and more effective than other algorithms in terms of efficiency and computational time. The numerical results proved that the SSA prevented premature convergence and 
Table 15. Simulation time comparison.

\begin{tabular}{|c|c|c|}
\hline Algorithm & Time/iteration (s) & Test case \\
\hline SSA & 0.046 & \multirow{4}{*}{ Test Case 1} \\
\hline TLBO [45] & 0.85 & \\
\hline CTLBO [45] & $\mathrm{NA}^{*}$ & \\
\hline AIS [45] & $\mathrm{NA}^{*}$ & \\
\hline SSA & 0.051 & \multirow{4}{*}{ Test Case 2} \\
\hline PSO-LRS [47] & 0.85 & \\
\hline APSO $[47]$ & $\mathrm{NA}^{*}$ & \\
\hline CBPSO-RVM [47] & $\mathrm{NA}^{*}$ & \\
\hline SSA & 0.041 & \multirow{5}{*}{ Test Case 3} \\
\hline ORCCRO [49] & 0.087 & \\
\hline SDE [50] & $\mathrm{NA}^{*}$ & \\
\hline $\mathrm{BBO}[49]$ & $\mathrm{NA}^{*}$ & \\
\hline DE/BBO [49] & 0.90 & \\
\hline SSA & 0.15 & \multirow{3}{*}{ Test Case 4(a) } \\
\hline EMA [51] & 0.23 & \\
\hline QPSO [51] & 0.54 & \\
\hline SSA & 0.07 & \multirow{4}{*}{ Test Case $4(\mathrm{~b})$} \\
\hline BBO [49] & 0.14 & \\
\hline DE/BBO [49] & 0.11 & \\
\hline ORCCRO [49] & 0.08 & \\
\hline SSA & 50.42 & \multirow{4}{*}{ Test Case 5} \\
\hline $\mathrm{BBO}[49]$ & 126.69 & \\
\hline DE/BBO [49] & 83.79 & \\
\hline ORCCRO [49] & 71.27 & \\
\hline
\end{tabular}

had a stable convergence characteristic. Hence, by using the exploration and exploitation properties of SSA, the problem of ELD was successfully solved.

\section{References}

1. Dhar R.N. and Mukherjee P.K. "Reduced-gradient method for economic dispatch", Electrical Engineers, Proceedings of the Institution of, 120(5), pp. 608-610 (1973).

2. Aoki, K. and Satoh, T. "Economic dispatch with network security constraints using parametric quadratic programming", IEEE Power Engineering Review, PER-2(12), pp. 37-38 (1982).

3. El-Keib, A.A., Ma, H., and Hart, J.L. "Environmentally constrained economic dispatch using the Lagrangian relaxation method", IEEE Trans Power Syst, 9(4), pp. 1723-1729 (1994).
4. Su, C.T. and Lin, C.T. "New approach with a Hopfield modeling framework to economic dispatch", IEEE Transactions on Power Systems, 15(2), pp. 541-545 (2000).

5. Jabr, R.A., Coonick, A.H., and Cory, B.J. "A homogeneous linear programming algorithm for the security constrained economic dispatch problem", IEEE Transactions on Power Systems, 15(3), pp. 930-936 (2000).

6. Swamp, K.S. and Natarajan, A. "Constrained optimization using evolutionary programming for dynamic economic dispatch", Proceedings of 2005 International Conference on Intelligent Sensing and Information Processing, pp. 314-319 (2005).

7. Farooqi, M., Jain, R.P., and Niazi, K.R. "Using Hopfield neural network for economic dispatch of power systems", Proceedings, National Power Engineering Conference, PECon 2003, pp. 5-10 (2003).

8. Reis Nascimento, M.H., Nunes, M.V.A., Rodriguez J.L.M., et al. "A new solution to the economical load dispatch of power plants and optimization using differential evolution", Electrical Engineering, 99(2), pp. 561-571 (2017).

9. Khatir, A.A., Motamedi, A., Sadati, N., et al. "Fuzzy economic dispatch and spinning reserve allocation using evolutionary programming", 40th North American Power Symposium, pp. 1-5 (2008).

10. Bavafa, M., Monsef, H., and Navidi, N. "A new hybrid approach for unit commitment using Lagrangian relaxation combined with evolutionary and quadratic programming", Asia-Pacific Power and Energy Engineering Conference, pp. 1-6 (2009).

11. Wang, Y., Zhou, J., Xiao, W., Zhang, Y. "Economic load dispatch of hydroelectric plant using a hybrid particle swarm optimization combined simulation annealing algorithm", Second WRI Global Congress on Intelligent Systems, 2, pp. 231-234 (2010).

12. Anand, H. and Narang, N. "Civilized swarm optimization for combined heat and power economic emission dispatch", 7th India International Conference on Power Electronics (IICPE), pp. 1-6 (2016).

13. Chaturvedi, K.T., Pandit, M., and Srivastava, L. "Particle swarm optimization with crazy particles for nonconvex economic dispatch", Appl Soft Comput., 9, pp. 962-969 (2009).

14. Lu, H., Sriyanyong, P., Song, Y.H., et al. "Experimental study of a new hybrid PSO with mutation for economic dispatch with non-smooth cost function", Int $J$ Electr Power Energy Syst., 32, pp. 921-935 (2010).

15. Niknam, T., Golestane, F., and Bahmanifirouzi, B. "Modified adaptive PSO algorithm to solve dynamic economic dispatch", IEEE Power Engineering and Automation Conference, 1 pp. 108-111 (2011).

16. King, D.J. and Oezveren Warsono, C.S. "A genetic algorithm based economic dispatch (GAED) with environmental constraint optimisation universities", Power Engineering Conference (UPEC), Proceedings of 2011 46th International, pp. 1-6 (2011). 
17. Al-Sumait, J.S. and Sykulski, J.K. "Solving economic dispatch problem using hybrid GA-PS-SQP method", IEEE EUROCON, pp. 333-338 (2009).

18. Amjady, N. and Nasiri-Rad, H. "Solution of nonconvex and non-smooth economic dispatch by a new adaptive real coded genetic algorithm", Expert Syst Appl., 37, pp. 5239-5245 (2010).

19. Hazra, J. and Sinha, A.K. "Environmental constrained economic dispatch using bacteria foraging optimization", Joint International Conference on Power System Technology and IEEE Power India Conference, pp. 1-6 (2008).

20. Maity, D., Banerjee, S., and Chanda, C.K. "Multiobjective economic emission load dispatch using modified biogeography based optimization algorithm", IEEE 7th Power India International Conference (PIICON), pp. 1-6 (2016).

21. Nagur, P.N., Raj, S., and Jadhav, H.T. "Modified artificial bee colony algorithm for non-convex economic dispatch problems", International Conference on Green Technologies (ICGT), pp. 258-262 (2012).

22. Shaw, B., Mukherjee, V., and Ghoshal S.P. "Seeker optimisation algorithm: application to the solution of economic load dispatch problems", IET Generation, Transmission \& Distribution, 5(1), pp. 81-91 (2011).

23. Rahmat, N., Musirin, A.I., Abidin, A.F., et al. "Economic load dispatch with valve-point loading effect by using differential evolution immunized ant colony optimization technique", Australasian Universities Power Engineering Conference (AUPEC), pp. 1-6 (2014).

24. Khamsawang, S., Pothiya S., and Boonseng, C., "Distributed tabu search algorithm for solving the economic dispatch problem", IEEE Region 10 Conference TENCON 2004, 3, pp. 484-487 (2004).

25. Maity, D., Banerjee, S., and Chanda, C.K. "Multiobjective economic emission load dispatch using modified biogeography based optimization algorithm", 2016 IEEE 7th Power India International Conference (PIICON), Page 1-6 (2016).

26. Roy, P.K. and Mandal, D. "Quasi-oppositional biogeography-based optimization for multi-objective optimal power flow", Electric Power Component System, 40, pp. 236-256 (2012).

27. Bhattacharya, A. and Chattopadhyay, P.K. "Oppositional biogeography-based optimization for multiobjective economic emission load dispatch", Annual IEEE India Conference (INDICON), pp. 1-6 (2010).

28. Arul, R., Velusami, S., and Ravi, G. "Solving combined economic emission dispatch problems using selfadaptive differential harmony search algorithm", International Conference on Circuits, Power and Computing Technologies [ICCPCT-2014], pp. 757-762 (2014).

29. Chatterjee, A., Ghoshal, S.P., and Mukherjee, V. "Solution of combined economic and emission dispatch problems of power systems by an opposition-based harmony search algorithm", Int J Electr Power Energy Syst., 39(1), pp. 9-20 (2012).
30. Ghosh, B., Dey, B., and Bhattacharya, A. "Solving economic load dispatch problem using hybrid Krill Herd algorithm", International Conference on Energy, Power and Environment: Towards Sustainable Growth (ICEPE) (2015).

31. Das, S., Bhattacharya, A., and Chakraborty, A.K. "Solution of short-term hydrothermal scheduling using sine cosine algorithm", Soft Computing, 22(6) (2017).

32. Qin, Q., Cheng, S., Chua, X., et al. "Solving nonconvex/non-smooth economic load dispatch problems via an enhanced particle swarm optimization", Applied Soft Computing, 59, pp. 229-242 (2017).

33. Roy, S. "The maximum likelihood optima for an economic load dispatch in presence of demand and generation variability", Energy, 147, pp. 915-923 (2018).

34. Roy, S., Bhattacharjee, K., and Bhattacharya, A. "A modern approach to solve of economic load dispatch using group leader optimization technique", International Journal of Energy Optimization and Engineering, IGI-Global, 6(1), pp. 66-85 (2016).

35. Bhattacharjee, K., Bhattacharya, A., and Halder, S. "Teaching learning based optimization for different economic dispatch problems", International Journal of Science and Technology, Scientia Iranica, 21(3), pp. 870-884 (2014).

36. Júnior, A.B., Jorge De, M.V.A., Nunes, M.H.R., et al. "Solution to economic emission load dispatch by simulated annealing: case study", Electrical Engineering, pp. 1-13 (2017).

37. Kaveh, A., Vaez, S.R.H., and Hosseini, P. "Enhanced vibrating particles system algorithm for damage identification of truss structures", Scientia Iranica, 26(1), pp. 246-256 (2017).

38. Singh, D. and Dhillon, J.S. "Ameliorated grey wolf optimization for economic load dispatch problem", Energy, 169, pp. 398-419 (2019).

39. Kumara, M. and Dhillon, J.S. "Hybrid artificial algae algorithm for economic load dispatch", Applied Soft Computing, 71, pp. 89-109 (2018).

40. Aghay Kaboli, S. Hr., and Abdullah, K.A. "Solving non-convex economic load dispatch problem via artificial cooperative search algorithm", Expert Systems with Applications, 128, pp. 14-27 (2019).

41. Gholamghasemi, M., Akbari, E., and Asadpoor, M.B. "A new solution to the non-convex economic load dispatch problems using phasor particle swarm optimization", Applied Soft Computing, 79, pp. 111-124 (2019).

42. Bhattacharjee, K., Shah, K., and Soni, J. "Solving economic dispatch using artificial Eco system-based optimization", Electric Power Components and Systems, Article in Press (2022). DOI: $10.1080 / 15325008.2021 .2013995$

43. Zhang, Q. , Zou, D., and Duan, N. "An adaptive differential evolutionary algorithm incorporating multiple 
mutation strategies for the economic load dispatch problem", Applied Soft Computing, 78, pp. 641-669 (2019).

44. Mirjalili, S., Gandomi, A.H., Mirjalili, S.Z., et al. "Salp swarm algorithm: A bio-inspired optimizer for engineering design problems", Advances in Engineering Software, 114, pp. 163-191(2017).

45. He, X., Rao, Y., and Huang, J. "Novel algorithm for economic load dispatch of power systems", Neurocomputing, 171, pp. 1454-1461 (2016).

46. Lu, H., Sriyanyong, P., Song, Y.H., et al. "Experimental study of a new hybrid PSO with mutation for economic dispatch with non-smooth cost function", Electrical Power and Energy Systems, 32, pp. 921-935 (2010).

47. Ali Bulbul, S.M., Pradhan, M., Roy, P.K. "Oppositionbased krill herd algorithm applied to economic load dispatch problem", Ain Shams Engineering Journal (2016).

48. Coelho, L.D.S. and Mariani, V.C. "Combining of chaotic differential evolution and quadratic programming for economic dispatch optimization with valvepoint effect", IEEE Trans Power System, 21(2), pp. 989-96 (2006).

49. Bhattacharjee, K., Bhattacharya, A., and Halder, S. "Oppositional real coded chemical reaction optimization for different economic dispatch problems", Electrical Power and Energy Systems, 55, pp. 378-391 (2014).

50. Reddy, S. and Vaisakh, K. "Shuffled differential evolution for large scale economic dispatch", Electric Power Syst Res., 96, pp. 237-245 (2013).

51. Ghorbani, N. and Babaei, E. "Exchange market algorithm for economic load dispatch", Electrical Power and Energy Systems, 75, pp. 19-27 (2016).

52. Sinha, N., Chakrabarti, R., and Chattopadhyay, P.K. "Evolutionary programming techniques for economic load dispatch", IEEE Trans Evol. Comput, 7(1), pp. 83-94 (2003).

53. Bhattacharjee, K., Bhattacharya, A., and Chattopadhyay, P.K. "Discussion on A GA-API solution for the economic dispatch of generation in power system operation", IEEE transaction on Power Systems, 28(1) (2013).

54. Roy, S. and Bhattacharjee, K. "The use of krill herd based optimization to solve complex economic load dispatch problems", Emerging Devices and Smart Systems (ICEDSS) (2017).

55. Rani, S., Roy, S., Bhattacharjee, K., et al. "Teaching learning based optimization to solve economic and emission scheduling problems", 2nd International
Conference on Control, Instrumentation, Energy \& Communication (CIEC) (2016).

56. Bhattacharjee, K., Bhattacharya, A., and Halder, S. "Chemical reaction optimization applied in economic dispatch problems", 1st International Conference on Automation, Control, Energy and Systems (ACES 14), Academic of Technology, Hooghly, India, 1(2), pp. 1-6 (2014).

57. Bhattacharjee, K. "Economic dispatch problems using backtracking search optimization", International Journal of Energy Optimization and Engineering, IGIGlobal, 7(2), Article-2, pp. 39-60 (2018).

58. Park, J., Jeong, Y., Shin, J., et al. "An improved particle swarm optimization for non-convex economic dispatch problems", IEEE Transactions on Power Systems, 25(1), pp. 156-166 (2010).

59. Huang, W.T., Yao, K.C., Chen, M.K., et al. "Derivation and application of a new transmission loss formula for power system economic dispatch", Energies, 11(2), p. 417 (2018).

60. Moradi-Dalvand, M., Mohammadi-Ivatloo, B., Najafi, A., et al. "Continuous quick group search optimizer for solving non-convex economic dispatch problems", Electric Power Systems Research, 93, pp. 93-105 (2012).

61. Mohammadi-Ivatloo, B., Rabiee, A., and Ehsan, S.M. "Iteration PSO with time varying acceleration coefficients for solving non-convex economic dispatch problems", Electrical Power and Energy Systems, 42, pp. 508-516 (2012).

\section{Biographies}

Kuntal Bhattacharjee received a BE degree from BIET, Suri Private College (Burdwan University) and MTech degree from NIT, Durgapur, India in 2003 and 2005, respectively, all in Electrical Engineering. He is currently at the Electrical Engineering Department, Institute of Technology, Nirma University, India. His research interests include power system optimization, ELD, EELD, and hydrothermal applications.

Nitish Patel received his BE degree from Babaria Institute of Technology under Gujarat Technological University and is currently pursuing his MTech in Electrical Power Systems from Institute of Technology, Nirma University, Ahmedabad, India. His research interests include artificial intelligence, power system optimization, economic load dispatch, and hydrothermal applications. 